\title{
T Cell Receptor-independent Immunosuppression Induced by Dexamethasone in Murine T Helper Cells
}

\author{
M. Rocío Sierra-Honigmann and Patrick A. Murphy \\ Division of Infectious Diseases, Department of Medicine, The Johns Hopkins University School of Medicine, Baltimore, Maryland 21205
}

\begin{abstract}
The immune and inflammatory responses are largely inhibited by glucocorticosteroids. In thymocytes, for example, glucocorticosteroids cause apoptosis, whereas they suppress the activity of phospholipase $A_{2}$ and the production of eicosanoids in tissues actively engaged in inflammation. The immunosuppressive action of dexamethasone (DEX) was studied in vitro by employing a model cell system, namely the murine Th2 clone D10.G4.1 (D10) and its clonotypic anti-T cell receptor (TCR) $\mathrm{mAb}$ 3D3. Although the proliferative response of $\mathrm{D} 10$ cells to 3D3 stimulation was not affected by DEX, the costimulation provided by IL-1 was dramatically inhibited. Substitution of $3 D 3$ by exogenous IL -4 (as the IL-1 costimulant) failed to prevent the inhibition of proliferation caused by DEX. Yet, when 3D3-mediated stimulation of TCR was supplemented with IL2, D10 cells were capable of proliferating, even in the presence of DEX. Thus, TCR stimulation on D10 cells remained intact and their resulting propagation was not compromised by DEX treatment. These results provide evidence that immunosuppression caused by DEX is TCR independent and involves an early cytokine-signalling event. (J. Clin. Invest. 1992. 89:556-560.) Key words: cytokines - interleukin-1 - glucocorticosteroids • D10.G4.1 cells $\bullet$ Th-signal transduction
\end{abstract}

\section{Introduction}

Glucocorticosteroids have multiple inhibitory effects on both the immune and inflammatory responses, but many aspects of these immunosuppressive actions are complex and poorly understood (1-5). For instance, it has been reported that corticosteroids inhibit IL- 2 synthesis and secretion in T helper cells, thereby preventing IL-2-dependent clonal expansion of activated cells $(2,6)$. On the other hand, suppression of both IL- $1 \alpha$ and IL- $1 \beta$ synthesis has been observed to result from treatment of mononuclear cells with pharmacological concentrations of corticosteroids (7-9).

The Th2 murine clone D10.G4.1 (D10) constitutes a convenient system with which to study immunoregulatory mechanisms, including the immunosuppressive action of glucocorticosteroids. The specific antigen for D10 cells is egg white conalbumin and their primary activation occurs when: (a) T cell

Address correspondence to M. Rocío Sierra-Honigmann, M.D., Division of Infectious Diseases, Department of Medicine, Johns Hopkins University School of Medicine, 600 North Wolfe Street, CMSC 1109, Baltimore, MD 21205.

Received for publication 6 August 1991.

J. Clin. Invest.

(C) The American Society for Clinical Investigation, Inc.

$0021-9738 / 92 / 02 / 0556 / 05 \$ 2.00$

Volume 89, February 1992, 556-560 receptor (TCR) ${ }^{1}$ is presented with antigen by antigen presenting cells (APC) in a manner restricted by $\mathrm{H}-2 \mathrm{k}$; (b) TCR is activated by the clonotypic monoclonal antibody 3D3; and (c) cells are treated with mitogenic lectins. Interleukin 1 potentiates the proliferative response subsequent to any of such routes of initial activation (10). Secondary stimuli are provided by the mature T cell growth factors, IL-4 and IL-2. Th2 cells, like D10 cells, synthesize and secrete IL-4 as their autocrine growth factor upon primary activation (11). Thus, the proliferative effect of IL-4 on D10 cells is regulated both by the steadystate levels of IL-4 produced and secreted, as well as by the expression of its cognate receptor (IL-4R) on the cell surface.

Cells of the Th2 type do not produce IL-2, but do respond to it when provided by a neighboring Th1 cell or by an exogenous source. The response of D10 cells to IL-2 is in turn regulated through its own receptor (IL-2R). Several reports by others, as well as our own observations, show that 3D3 stimulation of D10 cells causes IL- 4 synthesis and brings about IL-1 responsiveness. Importantly, the sensitivity of these cells to IL2 is markedly augmented when they become activated by 3D3 $(10,12)$.

In this report, we have employed the D10 cell system to study the immunosuppressive action of a potent synthetic glucocorticosteroid, i.e., dexamethasone (DEX). In particular, we examined the role of TCR in mediating DEX-induced immunosuppression and sought to correlate this effect with a specific cytokine signalling pathway(s). While proliferation of D10 cells stimulated with 3D3 remained unaffected by DEX, the classical growth enhancement due to simultaneous treatment with IL-1 and 3D3 was strongly inhibited. DEX also prevented the proliferative response brought about by IL-2 alone. However, when activation occurred through TCR stimulation induced by 3D3 supplemented with IL-2, D10 cells were able to divide normally, even in the presence of DEX. Thus, immunosuppression caused by DEX occurs independently from activation of $T$ cell receptor in a manner which appears to involve an early cytokine-regulated signalling pathway(s).

\section{Methods \\ Materials. The culture medium for the D10.G4.1 cells was Click's (Ir- vine Scientific, Santa Ana, CA) supplemented with $10 \%$ FBS (HyClone Laboratories, Logan, UT), $50 \mathrm{U} / \mathrm{ml}$ penicillin, $50 \mu \mathrm{g} / \mathrm{ml}$ streptomycin, $2 \mu \mathrm{M}$ glutamine, and $50 \mu \mathrm{M}$ 2-mercaptoethanol (complete medium). PHA-P was purchased from Difco Laboratories, Detroit, MI. Dexa- methasone and other reagents were from Sigma Chemical Co., St. Louis, MO. Mouse recombinant IL- $1 \alpha$ was a gift from Dr. P. Lome- dico, Hoffmann-LaRoche Inc., Nutley, NJ, and human recombinant IL-1 $\beta$ from Dr. C. Dinarello, Tufts University, Boston, MA. Glycosyl- ated mouse and human recombinant IL-2 were purchased from Gen- zyme Corp., Cambridge, MA. Mouse recombinant IL-4 was provided by Dr. S. Gillis, Immunex Corp., Seattle, WA. Crude gibbon IL-2 was}

1. Abbreviations used in this paper: APC, antigen-presenting cells; DEX, dexamethasone; TCR, T cell receptor. 
obtained from MLA-144 supernates and adjusted to $100 \mathrm{U} / \mathrm{ml}$ using a standard cytotoxic T lymphocyte growth assay $(12,13)$.

Cell culture and proliferation. The D10.G4.1 cell clone (No. TIB 224; American Type Culture Collection [ATCC], Rockville, MD) was cultured with some modifications to the original protocol (14). Briefly, D10 cells were stimulated with irradiated APC and antigen (conalbumin) every three weeks. They were maintained in complete Click's medium supplemented with 5\% stock MLA supernate as the source of IL-2. In preparation for proliferation assays, cells were deprived of IL-2 for at least $24 \mathrm{~h}$ by growing them in complete Click's without MLA supplement. Dead cells were removed by Ficoll-Hypaque gradient centrifugation (Sigma) and surviving cells (20-30\% of total) were dispensed into plastic culture wells at a density of $1 \times 10^{4}$ cells/well. Effectors were then added at the indicated concentrations either in the absence or presence of $1 \times 10^{-7} \mathrm{M}$ dexamethasone, unless otherwise indicated. In experiments requiring solid-phase 3D3 stimulation, purified $\mathrm{mAb}$ at $10 \mu \mathrm{g} / \mathrm{ml}$ in PBS was filter sterilized (with $0.22-\mu \mathrm{m}$ pore size filters), incubated in plastic tissue culture wells at $37^{\circ} \mathrm{C}$ for $1 \mathrm{~h}$, and then discarded. The wells were washed once with PBS before adding the cells and other reagents.

Proliferation assays were performed in 96-well plates using $1 \times 10^{5}$ cells $/ \mathrm{ml}$ in complete Click's medium. After $40 \mathrm{~h}$ in culture, $1.0 \mu \mathrm{Ci}$ of $\left[{ }^{3} \mathrm{H}\right] \mathrm{TdR}(20 \mathrm{Ci} / \mathrm{mmol}$; DuPont-New England Nuclear, Boston, MA) was added to every well and the incubation was continued for another 6 h. Cells were then harvested on glass fiber filters using a cell harvester (PHD; Cambridge Technology, Inc., Cambridge, MA) and the incorporated radioactivity was determined by liquid scintillation counting.

Cytofluorographic analysis. The 7D4 anti-murine IL-2R hybridoma (ATCC No. CRL 1698) was cultured in Dulbecco's modified Eagle's medium with $4.5 \mathrm{~g} /$ liter glucose, $10 \%$ FBS, supplemented with nonessential amino acids, sodium pyruvate and L-glutamine, at a density of $1 \times 10^{5}$ cells $/ \mathrm{ml}$. When the cultures reached cell densities between 1 and $2 \times 10^{6}$ cells $/ \mathrm{ml}$, supernates were harvested and diluted 10 -fold in PBS as the source of 7D4 mAb.

D10 cells were washed in PBS containing $0.01 \% \mathrm{NaN}_{3}$, adjusted to $10^{6}$ cells/tube in $0.1 \mathrm{ml} \mathrm{PBS}$, and treated with the 7D4 mAb-containing medium for $1 \mathrm{~h}$. At the end of this incubation, D10 cells were washed twice with cold PBS, resuspended, and treated with fluorescein isothiocyanate-labeled anti-rat IgM $\mu$ chain specific antibody (Jackson Immunoresearch Laboratories, West Grove, PA). Appropriate autofluorescence and second antibody controls were routinely used in separate tubes. After an incubation of $30 \mathrm{~min}$, cells were washed twice with PBS and then fixed with $0.1 \%$ paraformaldehyde in PBS. All of the above procedures were carried out at $4^{\circ} \mathrm{C}$. The flow-cytometric analysis was performed on an Epics Profile I flow cytofluorograph (Coulter Corp. Hialeah, FL).

\section{Results}

To determine whether DEX impairs primary activation through inhibition of TCR function or a cytokine-related mechanism, the proliferative response of D10 cells to 3D3 and various combinations of cytokines was studied upon treatment with DEX or not. As shown in Table I, TCR stimulation provided by $3 \mathrm{D} 3$ alone markedly increased the level of $\left[{ }^{3} \mathrm{H}\right] \mathrm{TdR}$ uptake, both in the absence or presence of DEX $(\sim 5$ - and 20 -fold, respectively). In addition, the synergistic proliferative response to both 3D3 and IL-2, although of moderate magnitude, was not affected by the glucocorticosteroid (Table I). In fact, the relative extent of stimulation of $\left[{ }^{3} \mathrm{H}\right] \mathrm{TdR}$ uptake (with respect to "basal" proliferation) induced by 3D3 or 3D3 and IL-2 in the presence of DEX, appears to be greater than that of their corresponding controls without DEX (Table I, lines 2 and 3 ). This effect clearly occurs at the expense of a $72 \%$ reduction in the basal level of thymidine uptake, which could be attributed to primary DEX-associated toxicity (3). However, the fact
Table I. Effect of Dexamethasone on D10.G4.1 T Cell Clone Proliferation

\begin{tabular}{lccc}
\hline & \multicolumn{2}{c}{ [ $\left.^{3} \mathrm{H}\right] \mathrm{TdR}$ uptake* } & \\
\cline { 2 - 3 } \multicolumn{1}{c}{ Effectors } & Untreated & DEX-treated & Inhibition \\
\hline & $c p m$ & $c p m$ & $\%$ \\
None & $467 \pm 19$ & $131 \pm 20$ & 72 \\
3D3 $^{\ddagger}$ & $2,473 \pm 253$ & $2,616 \pm 215$ & 0 \\
3D3 + IL-2 & $6,220 \pm 1,042$ & $7,540 \pm 1,211$ & 0 \\
3D3 + IL-1 $\alpha^{\S}$ & $146,935 \pm 11,133$ & $15,278 \pm 3,841$ & 90 \\
3D3 + IL-1 $\beta$ & $122,917 \pm 10,561$ & $22,838 \pm 2,138$ & 81 \\
IL-1 $\alpha+$ IL-4 & $53,640 \pm 4,460$ & $1,889 \pm 247$ & 96 \\
3D3 + IL-1 $\alpha+$ IL-4 & $114,500 \pm 1,165$ & $3,814 \pm 460$ & 97 \\
& & & \\
\hline
\end{tabular}

* Data are the mean \pm SEM; $n=4$. ${ }^{\ddagger}$ Purified 3D3 was previously immobilized on tissue culture wells as described in Methods. ${ }^{\S}$ Cytokines were used at the following concentrations: IL- $1 \alpha$ and IL- $1 \beta$, $10^{-8} \mathrm{M}$; IL-2, $25 \mathrm{U} / \mathrm{ml}$; IL-4, $30 \mathrm{U} / \mathrm{ml}$.

that 3D3-treated D10 cells remained sensitive to IL-2 in the presence of DEX implies that they are functionally competent, even when exposed to the glucocorticosteroid (Table I and Fig. $3 \mathrm{~B}$ ). Therefore, suppression of cell growth in D10 cells treated with DEX cannot be explained simply on the basis of cytotoxicity. This observation also suggests that, in 3D3-treated cells, IL-2 is able to provide a protective effect against DEX-induced inhibition of proliferation (see below).

In contrast to the lack of effect of DEX upon IL-2-assisted growth stimulation, the steroid dramatically inhibited proliferation of D10 cells costimulated with $3 \mathrm{D} 3$ and either IL- $1 \alpha$ or IL- $1 \beta$. These cytokines exhibited their characteristic strong potentiation of 3D3 stimulation in cells not treated with DEX (Table I).

To further investigate the possibility that DEX impairs IL-1 action in D10 cells, the facilitative effect of this cytokine upon the proliferative response to IL-4 was examined. It has been shown that D10 cells produce and secrete IL-4, but not IL-2, as their autocrine growth factor upon antigen presentation (11). In addition, these cells divide in response to IL-4, when added exogenously in combination with IL-1 (12). Moreover, this IL1/IL-4 costimulation occurs without a concomitant antigenic challenge and it resembles the proliferative effect observed when cells are treated with both 3D3 and IL-1. Although the nature of this effect still awaits elucidation, it clearly indicates a role for IL-1 in the regulation of biological responsiveness to IL-4, and thus serves as an experimental tool to monitor biological sensitivity to IL-1. As shown in Table I, DEX treatment caused a virtually complete inhibition of the synergy between IL- $1 \alpha$ and IL-4 to elicit a substantial proliferative response. This inhibition was also seen when D10 cells were simultaneously stimulated with 3D3, IL-1 $\alpha$, and IL-4 (Table I). However, the level of $\left[{ }^{3} \mathrm{H}\right] \mathrm{TdR}$ uptake observed in this case was never below that corresponding to treatment with 3D3 alone, thereby suggesting that DEX induces a more direct suppression of the IL-1-facilitated response to IL-4.

The inhibition of the biological response to IL-1 caused by DEX was also studied as a function of the concentration of cytokine. In D10 cells stimulated with 3D3, IL-1 elicits its potentiating effect with a characteristic concentration depen- 


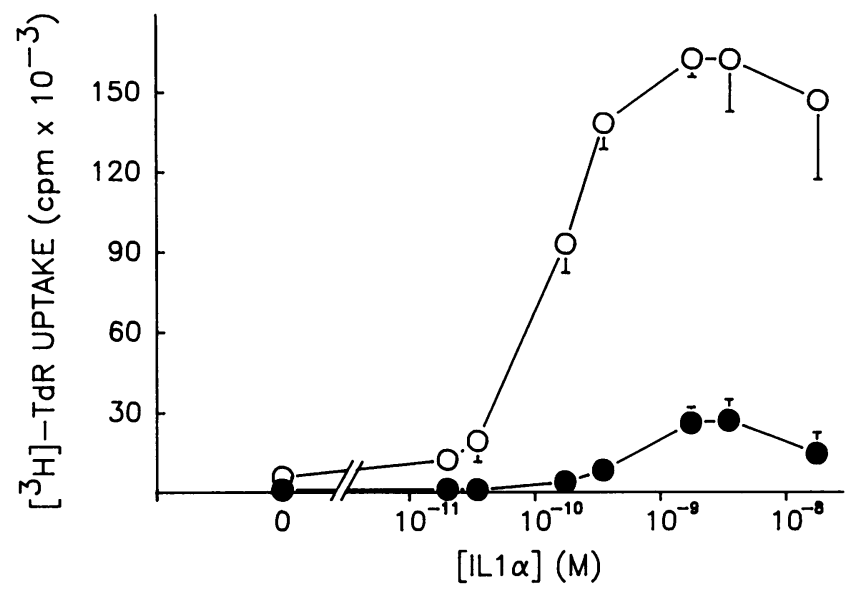

Figure 1. Inhibition of IL-1 costimulation of D10.G4.1 cells by dexamethasone. D10 cells were costimulated with various concentrations of murine rIL- $1 \alpha$ and solid phase-bound 3D3 $\mathrm{mAb}$ in the presence (•) or absence (O) of $1 \times 10^{-7} \mathrm{M}$ DEX. Data are expressed as [ $\left.{ }^{3} \mathrm{H}\right] \mathrm{TdR}$ incorporated (cpm) from a representative experiment (mean \pm SEM, $n=4$ ). Similar results were observed in four independent experiments.

dence, which is severely affected by DEX. Potent inhibition of $\left[{ }^{3} \mathrm{H}\right] \mathrm{TdR}$ uptake by the steroid was observed at all concentrations of IL-1 that were tested (Fig. 1).

The suppression of IL-1 action by DEX is concentration dependent (Fig. 2). Thus, when 3D3-stimulated D10 cells were treated with IL-1 and increasing concentrations of DEX, proliferation was steadily inhibited, even at $100 \mathrm{pM}(25 \%$ inhibition). Importantly, none of the concentrations of DEX tested prevented significantly the response of D10 cells to IL-2.

Since cytokines usually exert their physiological actions concomitantly with antigenic activation of the $\mathrm{T}$ cell receptor, it is difficult to distinguish separate signalling events which originate directly from each stimulating component. Nevertheless, treatment of D10 cells with IL-2 alone (in the absence of 3D3) gives rise, by itself, to a substantial proliferative response that exhibits a characteristic concentration-dependence on the cytokine (Fig. $3 \mathrm{~A}$ ). However, this effect (which clearly does not involve TCR activation) was completely abrogated by DEX treatment (Fig. $3 A$ ). In contrast, and as pointed out earlier (see Table I and Fig. 2), stimulation of D10 cell growth can occur normally upon IL-2 addition to 3D3-stimulated cells, even in the presence of DEX (Fig. $3 \mathrm{~B})$. $^{2}$ Thus, suppression of IL-2-stimulated cell growth by DEX takes place in the absence of activation of the $T$ cell receptor, thereby implicating a perturbation of the IL-2 (but not the TCR) signalling pathway.

To determine whether the ability of DEX to prevent IL-2induced cell proliferation is due to changes in the IL-2R, we examined the cellular level of this macromolecule upon steroidal treatment. For these experiments, we employed a monoclonal antibody (7D4) directed against the $55-\mathrm{kD} \alpha$ subunit of the IL-2R and estimated the number of D10 cells bearing this receptor on the cell surface by cytofluorographic analysis (see

2. Diminished proliferation of D10 cells treated with 3D3 and IL-2 in the presence of DEX begins to be apparent above $40 \mathrm{U} / \mathrm{ml}$ of IL-2, which may be explained by depletion of nutrients or other endogenous growth factors.

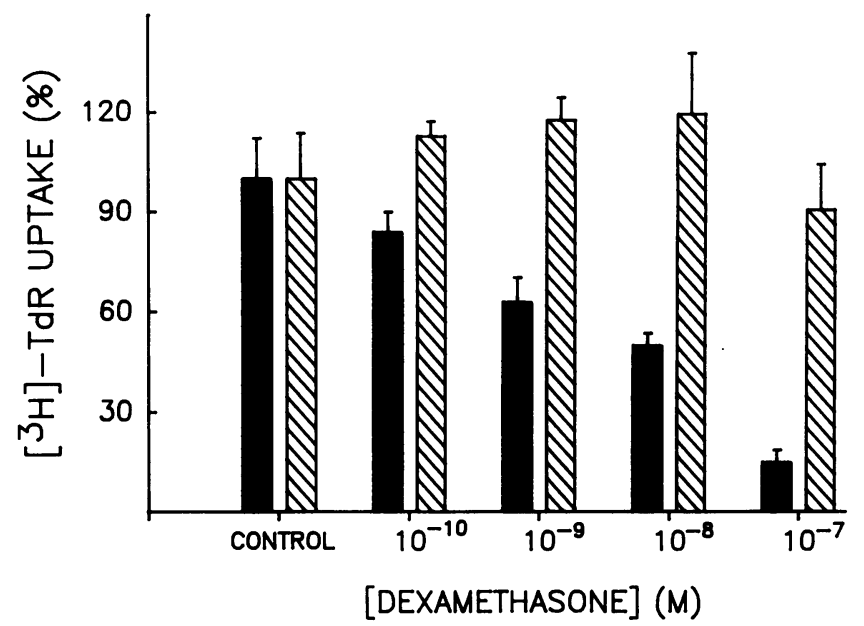

Figure 2. Concentration dependence of inhibition of synergistic IL-1TCR response by dexamethasone. D10 cells were treated with the indicated concentrations of DEX and a fixed concentration of rIL- $1 \alpha$ $\left(1 \times 10^{-9} \mathrm{M}\right.$; filled bars $)$ or rIL-2 $(25 \mathrm{U} / \mathrm{ml}$; cross-hatched bars). Proliferation assays were performed on 3D3-coated culture wells as described in Methods. Results are expressed as percentage of maximal $\left[{ }^{3} \mathrm{H}\right] \mathrm{TdR}$ incorporation, representing three independent experiments (mean \pm SEM, $n=12$ ). $₫$, IL1/3D3; $\mathbb{a} ;$ IL2/3D3.

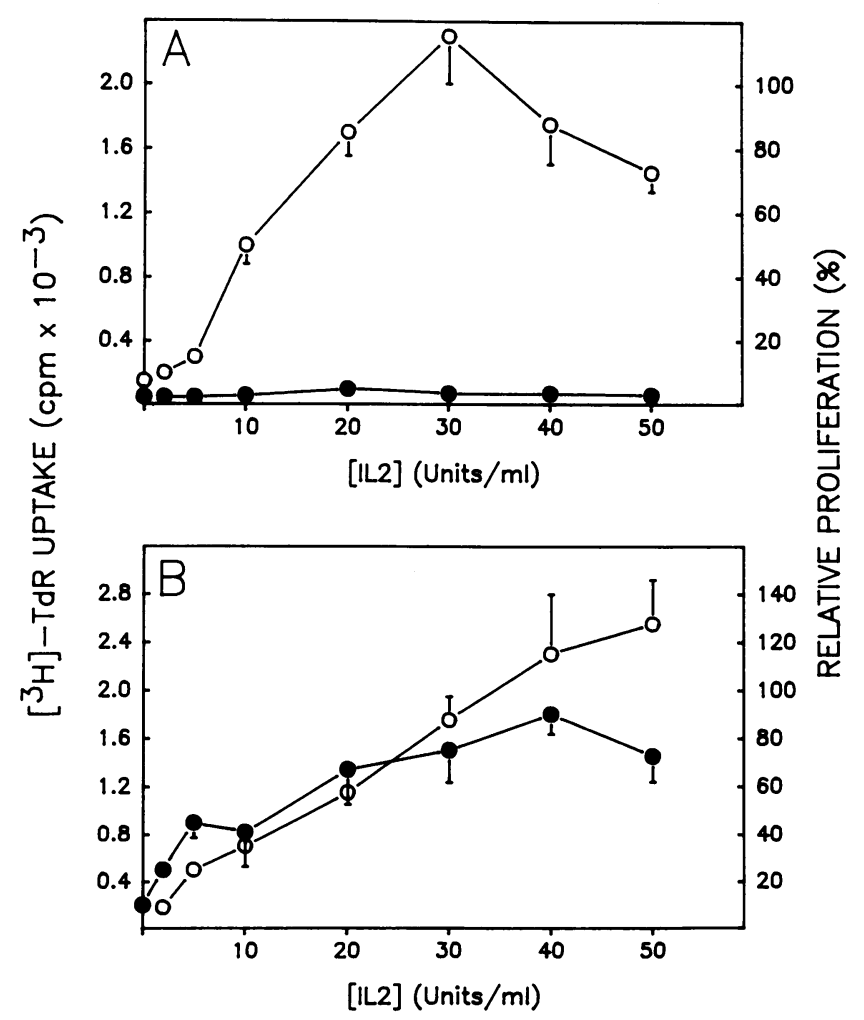

Figure 3. Differential inhibition of IL-2-dependent proliferation by dexamethasone in 3D3-treated vs. untreated cells. D10 cells were treated with IL-2 alone $(A)$ or IL-2 with solid phase-bound purified $3 \mathrm{D} 3(B)$, in the absence $(0)$ or presence $(\bullet)$ of DEX $\left(1 \times 10^{-7} \mathrm{M}\right)$, which was added $4 \mathrm{~h}$ before all other stimuli. Data are expressed as $\left[{ }^{3} \mathrm{H}\right] \mathrm{TdR}$ uptake (cpm) from a representative experiment $($ mean \pm SEM, $n=4)$. Equivalent results were observed in three independent experiments. 
Methods). As shown in Fig. $4 A$, treatment of D10 cells with DEX alone did not significantly change the cellular level of IL-2R. Moreover, upon stimulation of D10 cells with 3D3 for $18 \mathrm{~h}$, the content of IL-2R increased appreciably as expected, irrespective of the presence or absence of DEX.
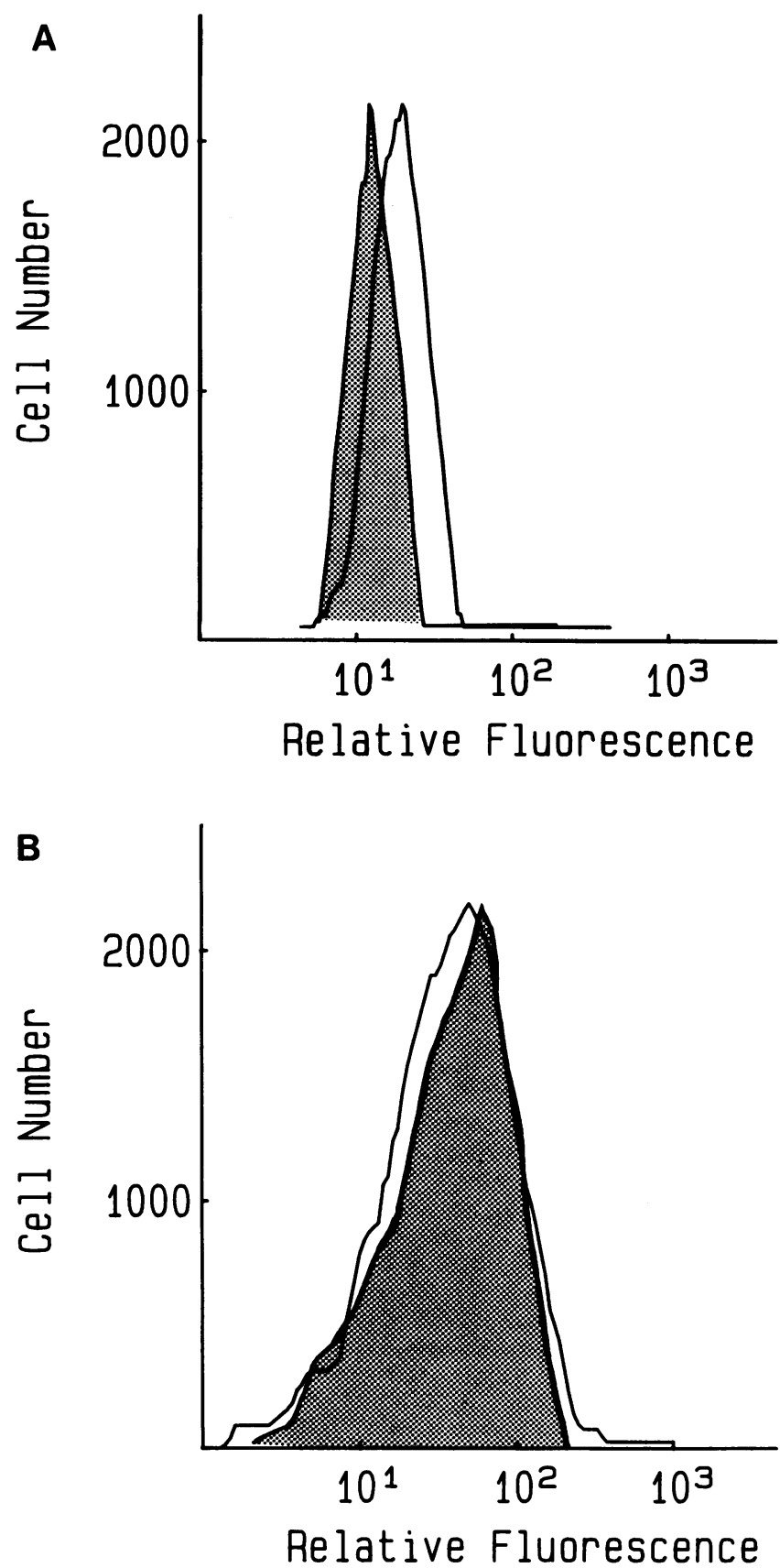

Figure 4. Effect of dexamethasone on cell surface-associated IL-2 receptor. D10 cells were left either untreated $(A)$ or incubated with solid phase-bound 3D3 for $18 \mathrm{~h}(B)$, in the absence (solid line) or presence (shaded area) of DEX $\left(1 \times 10^{-7} \mathrm{M}\right)$. Cells were then washed, incubated with 7D4 mAb, and treated with FITC-conjugated anti-rat IgM $\mu$ chain specific antibody. The content of IL-2R was determined by flow cytofluorography, as described in Methods. Results are expressed as relative fluorescence and are representative of four independent experiments.

\section{Discussion}

Glucocorticoids are known to induce severe lymphopenia, markedly affecting the $T$ cell subpopulation (15). Inhibition of proliferation of mononuclear cells by pharmacological doses of glucocorticoids also occurs when used both in vivo and in vitro. They also inhibit synthesis of IL-2 in Th1 cells, and the production of IL- $1 \alpha$ and IL- $1 \beta$ by adherent mononuclear cells is also blocked (2, 7-9). Yet the precise mechanism by which immunosuppression of the helper $\mathrm{T}$ cell occurs has remained unclear.

In this study, we have examined the mechanism of immunosuppression caused by the potent glucocorticoid dexamethasone on murine Th2 D10 cells, a model cellular system for studying immunomodulation in vitro. Our findings indicate that DEX produced an inhibition of cytokine-assisted D10 cell proliferation, irrespective of activation of the $T$ cell receptor. First, cell growth induced by stimulating D10 cells with 3D3 alone was not appreciably affected by dexamethasone (Table I). Second, stimulation of D10 cells by IL- 1 or IL- $1 \alpha$ and IL-4 (a combination used to indirectly monitor IL-1 action) in the absence of 3D3, was suppressed by DEX (Table I and Fig. 3). Third, the proliferative response due to costimulation by $3 \mathrm{D} 3$ and IL- $1 \alpha$, IL- $1 \beta$, or by the combination IL- $1 \alpha / \mathrm{IL}-4$, could be presented by the glucocorticosteroid as well (Table I). Thus, proliferation of D10 cells in response to at least the cytokines IL-1 and IL-2 is blocked by glucocorticoids through a mechanism that does not involve inhibition of $\mathrm{T}$ cell receptor function. In fact, stimulation of TCR by 3D3 renders D10 cells refractory to suppression of IL-2-induced growth caused by dexamethasone (Fig. 3 B).

Although the nature of this "protective" effect against inhibition of cell growth by DEX remains elusive, it is not the result of differences in the cellular level of IL-2 receptors which were found to be unchanged by DEX treatment, whether or not 3D3 was present (Fig. 4). In a global context, however, it may be possible that the well known inhibition of IL-2 synthesis by glucocorticosteroids in Th1 cells (2) plays an important role in blunting the immune response. This effect, together with the disruption of cytokine signalling shown to occur in $\mathrm{Th} 2$ cells in this report, could be key elements that bring about overall immunosuppression in the intact animal. A similar protective effect of IL-2 on DEX-induced DNA fragmentation and cell death has been reported (16). Furthermore, reversion of steroid immunosuppression by IL-2 has been previously observed in mitogen-stimulated human peripheral mononuclear cells and mouse spleen cells, as well as in the effector function of mouse cytotoxic $T$ lymphocyte generated in vivo and in vitro $(4,6$, 17-20).

When D10 cells are activated through TCR stimulation, their proliferative rate becomes maximal within a few hours. They synthesize and secrete their autocrine growth factors (i.e., IL-4), and respond to other growth-inducing cytokines that may be present in the medium, such as IL- 2 from Th 1 cells. Because of their clonal nontransformed nature, D10 cells need to be activated with antigen every two to three weeks to keep them viable in culture. Also, they require continuous supplementation with IL-2 to sustain their growth. In a previous study where D10 cells were treated with DEX, opposite results to our observations were found (21). A major difference between that report and our study consists in the source and preparation of D10 cells. As indicated by the authors, while their cells were harvested during the active growth phase and 
kept frozen until needed, we consistently employed cells constantly kept in culture and that were at least 20 days post-antigenic stimulation. These "quiescent" cells more closely resemble the Th cells that become activated in vivo thereby constituting the optimal cell system for IL-1 assays. However, all dead cells must be removed before the assay (the onset of growth arrest can be determined microscopically), such that surviving cells can respond to very low concentrations of IL-1 in the presence of 3D3. Although the authors of the report mentioned above claim that their D10 cells were functionally intact after freezing/thawing it is conceivable that since their cells were actively growing at the time they were collected, they did not reach the state of quiescence required for these experiments. It is certainly difficult to reconcile their results with the widely recognized immunosuppressive character of DEX which, in their hands, not only caused proliferation of D10 cells, but also completely failed to inhibit the effects of IL- $1 \alpha$ or IL- $1 \beta$. In our experiments, DEX is capable of blocking responses to all lymphokines when given alone, but does not impair TCR activation. Furthermore, we report here for the first time a selective inhibition by DEX of the IL-1/3D3 costimulatory action in T cells.

Finally, several recent reports have shown that the DNAbinding ability of the ligand-bound glucocorticoid receptor is impaired by interaction with the Fos/Jun complex or AP-1 complex (22-25). Since IL-1 has been reported to induce c-jun mRNA (26), its pleiotropic effects could be the result of the expression of various AP-1-regulated genes. In this context, therefore, we speculate that corticosteroids would be antagonic to most, if not all, IL-1 biological actions. Further work will be necessary to ascertain the action of IL-1 at the genomic level, as well as to the role of changes in other growth factor receptors and their signalling pathways (i.e., IL-1 and IL-4) in immunosuppression caused by glucocorticoids.

\section{References}

1. Daynes, R. A., and B. A. Araneo. 1989. Contrasting effects of glucocorticoids on the capacity of $T$ cells to produce the growth factors interleukin 2 and interleukin 4. Eur. J. Immunol. 19:2319-2325.

2. Gillis, S., G. R. Crabtree, and K. A. Smith. 1979. Glucocorticoid-induced inhibition of $\mathrm{T}$ cell growth factor production. I. The effect on mitogen-induced lymphocyte proliferation. J. Immunol. 123:1624-1631.

3. Wyllie, A. H. 1980. Glucocorticoid-induced thymocyte apoptosis is associated with endogenous endonuclease activation. Nature (Lond.). 284:555-556.

4. Cupps, T. R., and A. S. Fauci. 1982. Corticosteroid-mediated immunoregulation in man. Immunol. Rev. 65:133-155.

5. Fahey, J. V., P. M. Guyre, and A. Munck. 1981. Mechanisms of antiinflammatory actions of glucocorticoids. Adv. Inflammation Res. 2:21-51.

6. Gillis, S., G. R. Crabtree, and K. A. Smith. 1979. Glucocorticoid-induced inhibition of T cell growth factor production. II. The effect on the in vitro generation of cytolytic T cells. J. Immunol. 123:1632-1638.

7. Ortega, G., R. J. Robb, E. M. Shevach, and T. R. Malek. 1984. The murine IL 2 receptor. I. Monoclonal antibodies that define distinct functional epitopes on activated T cells and react with activated B cells. J. Immunol. 133:1970-1975.
8. Ashwell, J. D., R. J. Robb, and T. R. Malek. 1986. Proliferation of T lymphocytes in response to interleukin 2 varies with their state of activation. $J$. Immunol. 137:2572-2578.

9. Lew, W., J. J. Oppenheim, and K. Matsushima. 1988. Analysis of the suppression of IL-1 alpha and IL-1 beta production in human peripheral blood mononuclear adherent cells by a glucocorticoid hormone. J. Immunol. 140:1895-1902.

10. Kaye, J., S. Gillis, S. B. Mizel, E. M. Shevach, T. R. Malek, C. A. Dinarello, L. B. Lachman, and C. A. Janeway, Jr. 1984. Growth of a cloned helper T cell line induced by a monoclonal antibody specific for the antigen receptor: interleukin 1 is required for the expression of receptors for interleukin 2. J. Immunol. 133:1339-1345.

11. Lichtman, A. H., E. A. Kurt-Jones, and A. K. Abbas. 1987. B-cell stimulatory factor 1 and not interleukin 2 is the autocrine growth factor for some helper $\mathrm{T}$ lymphocytes. Proc. Natl. Acad. Sci. USA. 84:824-827.

12. Kurt-Jones, E. A., S. Hamberg, J. Ohara, W. E. Paul, and A. K. Abbas. 1987. Heterogeneity of helper/inducer T lymphocytes. I. Lymphokine production and lymphokine responsiveness. J. Exp. Med. 166:1774-1787.

13. Rabin, H., R. F. Hopkins, III, F. W. Ruscetti, R. H. Neubauer, R. L. Brown, and T. G. Kawakami. 1981. Spontaneous release of a factor with properties of $\mathrm{T}$ cell growth factor from a continuous line of primate tumor T cells. $J$. Immunol. 127:1852-1856.

14. Kaye, J., S. Porcelli, J. Tite, B. Jones, and C. A. Janeway, Jr. 1983. Both a monoclonal antibody and antisera specific for determinants unique to individual cloned helper $\mathrm{T}$ cell lines can substitute for antigen and antigen-presenting cells in the activation of T cells. J. Exp. Med. 158:836-856.

15. Fauci, A. S., and D. C. Dale. 1974. The effect of in vivo hydrocortisone on subpopulations of human lymphocytes. J. Clin. Invest. 53:240-246.

16. Nieto, M. A., and A. Lopez-Rivas. 1989. IL-2 protects T lymphocytes from glucocorticoid-induced DNA fragmentation and cell death. J. Immunol. 143:4166-4170.

17. Schleimer, R. P., A. Jacques, H. S. Shin, L. M. Lichtenstein, and M. Plaut. 1984. Inhibition of T cell-mediated cytotoxicity by anti-inflammatory steroids. $J$. Immunol. 132:266-271.

18. Larsson, E. L. 1980. Cyclosporin A and dexamethasone suppress T cell responses by selectively acting at distinct sites of the triggering process. $\mathrm{J}$. Immunol. 124:2828-2833.

19. Munk, A., and P. M. Guyre. 1986. Glucocorticoids, physiology, pharmacology and stress. In Steroid Hormone Resistance. G. P. Chrousos, D. L. Loriaux, and M. B. Lipsett, editors. Plenum Publishing Corp., New York. 81-96.

20. Cupps, T. R. 1989. Effects of glucocorticoids on lymphocyte function. In Anti-inflammatory Steroid Action. R. P. Schleimer, H. N. Claman, and A. L. Oronsky, editors. Academic Press, Inc., San Diego, CA. 132-150.

21. Bertoglio, J. H., and E. Leroux. 1988. Differential effects of glucocorticoids on the proliferation of a murine helper and a cytolytic $\mathrm{T}$ cell clone in response to IL-2 and IL-4. J. Immunol. 141:1191-1196.

22. Diamond, M. I., J. N. Miner, S. K. Yoshinaga, and K. R. Yamamoto. 1990. Transcription factor interactions: selectors of positive or negative regulation from a single DNA element. Science (Wash. DC). 249:1266-1272.

23. Yang-Yen, H. F., J. C. Chambard, Y. L. Sun, T. Smeal, T. J. Schmidt, J. Drouin, and M. Karin. 1990. Transcriptional interference between c-Jun and the glucocorticoid receptor: mutual inhibition of DNA binding due to direct proteinprotein interaction. Cell. 62:1205-1215.

24. Jonat, C., H. J. Rahmsdorf, K. K. Park, A. C. Cato, S. Gebel, H. Ponta, and P. Herrlich. 1990. Antitumor promotion and antiinflammation: downmodulation of AP-1 (Fos/Jun) activity by glucocorticoid hormone. Cell. 62:1189-1204.

25. Schule, R., P. Rangarajan, S. Kliewer, L. J. Ransone, J. Bolado, N. Yang, I. M. Verma, and R. M. Evans. 1990. Functional antagonism between oncoprotein c-Jun and the glucocorticoid receptor. Cell. 62:1217-1226.

26. Muegge, K., T. M. Williams, J. Kant, M. Karin, R. Chiu, A. Schmidt, U. Siebenlist, H. A. Young, and S. K. Durum. 1989. Interleukin-1 costimulatory activity on the interleukin-2 promoter via AP-1. Science (Wash. DC). 246:249251 . 